\title{
An opportunity taken: Sunshine Coast University Private Hospital's Perioperative Nurse Surgeon's Assistant experience
}

Follow this and additional works at: https://www.journal.acorn.org.au/jpn

Part of the Health Services Administration Commons, Health Services Research Commons, Perioperative, Operating Room and Surgical Nursing Commons, and the Surgery Commons

(c) (1)

This work is licensed under a Creative Commons Attribution 4.0 License.

\section{Recommended Citation}

Smith, Catherine; Hains, Toni; and Mannion, Natasha (2016) "An opportunity taken: Sunshine Coast University Private Hospital's Perioperative Nurse Surgeon's Assistant experience," Journal of Perioperative Nursing: Vol. 29 : Iss. 3 , Article 1.

Available at: https://doi.org/10.26550/2209-1092.1005

https://www.journal.acorn.org.au/jpn/vol29/iss3/1

This Article is brought to you for free and open access by Journal of Perioperative Nursing. It has been accepted for inclusion in Journal of Perioperative Nursing by an authorized editor of Journal of Perioperative Nursing. 


\section{Authors}

Catherine Smith

MNPracSt, GradDipClinSc (PNSA), RN

Toni Hains

MNPracSt, MClinSc (PNSA), RN

Natasha Mannion

MClinSc (PNSA) RN

\section{Corresponding author}

Toni Hains

MNPracSt, MClinSc (PNSA), RN

\section{An opportunity taken: Sunshine Coast University Private Hospital's Perioperative Nurse Surgeon's Assistant experience}

The Ramsay Health Care facility, Sunshine Coast University Private Hospital (SCUPH), opened on the $4^{\text {th }}$ of November 2013. The facility has six operating theatres offering surgical services in orthopaedics; ear, nose and throat; general; urology; gynaecology and gastroenterology'. The private hospital will be co-located on the site of the pending public hospital, Sunshine Coast University Hospital, on the Kawana Health Campus².

Prior to opening the services at SCUPH, the perioperative Assistant Director of Nursing (ADON) spoke with one of the local Perioperative Nurse Surgeon's Assistants (PNSA) about the potential of using the skills of PNSAs for public operating lists on the private campus.

Recent communication with the (then) ADON (who has recently retired) revealed her reasons for exploring the potential use of PNSAs were:

- uncertainty of medical resident or registrar allocation to the SCUPH campus (particularly to the operating theatres)

- previous positive experiences with PNSAs in the private sector

- upon contacting local general practitioners in the area, she found the remuneration rate and availability for lists of public list intra-operative assisting services was not aligned to the SCUPH business plan for conducting the public/private contract

- most surgeons who had been contacted thought trained, registered nurses would work well.
The peak body for operating room nurses in Australia, the Australian College of Perioperative Nurses (ACORN), recognises the role of nurses who perform surgical assisting duties and, in 2014, updated their standard on this role. According to this standard the PNSA provides surgical care for the preoperative, intraoperative and postoperative phases of patient care delivery ${ }^{3}$. SCUPH was looking to utilise care provided by the PNSA in the intraoperative phase.

The first operating list to use this mode of care delivery was an orthopaedic surgeon's list in late 2013. A two-month trial was established to assess if PNSA intraoperative care met the needs of the patients, surgeons and the hospital'.

Currently fourteen PNSAs are credentialed and support SCUPH to meet the conditions of a public/ private contract. On any given day as many as five PNSAs may be servicing all but one of the six operating theatres'. 


\section{Background}

In Australia, nurses who perform the role of surgical assistant form part of the international classification of non-medical surgical assistants. The non-medical surgical assistant has many incarnations in the global arena. Not all of the personnel who perform the role of non-medical surgical assistant internationally are registered nurses ${ }^{4-11}$.

From a review of the literature, it is proposed that only registered nurses perform the role of non-medical surgical assistant in Australia ${ }^{12-14}$. It is anticipated that this role has been practiced in the Australian health care system for in excess of 15 years but the number of documents in the form of research, journal articles, government policy or legislation pertaining to this role is negligible ${ }^{15}$. Brennan proposed in 2001 that the advanced practice of perioperative nurses incorporating the role of surgical first assistant had the ability to provide cost-effective and versatile patient care in the Australian health care system ${ }^{15}$. As recently as 2014, a Queenslandbased study on the justification and utilisation of the nursing workforce stated that the expertise, capability and experience of nurses and the relevance of these to their role should not be undervalued ${ }^{16}$.

The PNSA role in Australia was initially established in $2001^{15}$. While a master's degree with a surgical assisting (PNSA) strand is offered at one university in Australia, candidates until recently could qualify at the graduate certificate or graduate diploma level if desired. Currently students may attain a graduate diploma or master's level qualification ${ }^{17}$.

It appears the only other nonmedical surgical assistant role currently in Australia is that of the
Nurse Practitioner (NP) $)^{13,14}$. This protected title is, arguably, the most significant of advanced practice nursing roles ${ }^{18}$. The designation of NP is recognised by the Australian Health Professionals Regulation Agency (AHPRA). A high proportion of NPs working in the perioperative area refer to themselves as Perioperative Nurse Practitioners (PNP).

Although most PNSAs in Australia work in the private sector, remuneration is problematic. PNSAs with no NP qualification do not have a Medicare provider number so are not able to access the Medical Benefits Schedule (MBS) ${ }^{19}$. NPs have access to limited MBS item numbers which don't encompass procedural item numbers or the 'Assisting at operation' MBS item series.

For convenience in this paper, both the roles of the PNSA and the PNP will be referred to as PNSA.

\section{Data collection}

Three surveys were created: one targeted PNSAs, one was specifically for surgeons and one was to gain an insight into the thoughts of perioperative staff employed in the operating theatres of SCUPH. Data was collected in January and February of 2015. This was approximately 14 months after PNSA services commenced at SCUPH. Participation was voluntary. Surveys collected demographic and qualitative data. The aim of these surveys of personnel on campus of SCUPH was to measure the customer service provided by PNSAs within the operating theatres. Permission for this study was granted by the Perioperative Management Team.

Participation was voluntary and surveys could be completed anonymously if required.

\section{Response rate}

Twelve PNSAs (85 per cent), thirteen surgeons (100 per cent at the time the survey was administered) and thirty-five SCUPH perioperative staff (70 per cent) completed and returned a survey. Perioperative staff included nurse unit managers, registered nurses, enrolled nurses and anaesthetic technicians.

\section{Results}

\section{Perioperative staff}

Of the perioperative staff who completed the survey, the mean years of perioperative experience were eleven ( $s=9$ ). Seventy-four per cent of respondents were aware of the role of the PNSA prior to their experience at SCUPH and 98 per cent 'liked' having a PNSA in their theatre. Over half (54 per cent) of the perioperative nurses who responded had thought about gaining a qualification to work as a PNSA.

Eighty-three per cent of perioperative staff who completed the survey thought that PNSAs had a high impact as a resource in theatre, 87 per cent thought that PNSAs had a high or moderately high impact on leadership and 97 per cent thought the PNSAs' contribution to patient positioning and 'set-up' was high to moderately high (Figure 1).

\section{Comments made by perioperative staff:}

'We love PNSAs. More in tune with what the scrub nurse is doing. Help us with getting ready - very helpful.'

'Love having them here, makes our job easier.'

'Love having them. I have tried to talk other surgeons into using a PNSA over medical assistants as they are much more helpful.'

'Some difficulty with role delineation with some PNSAs and scrub nurses.' 


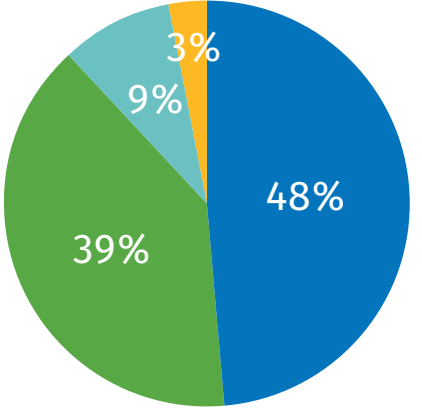

Leadership

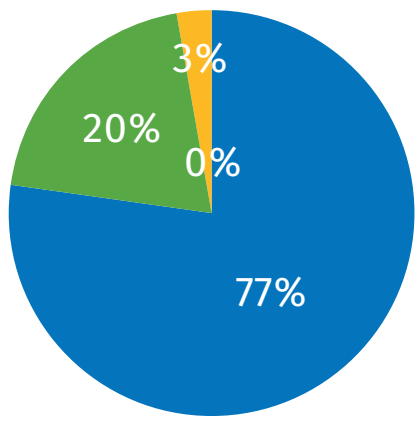

Patient set-up

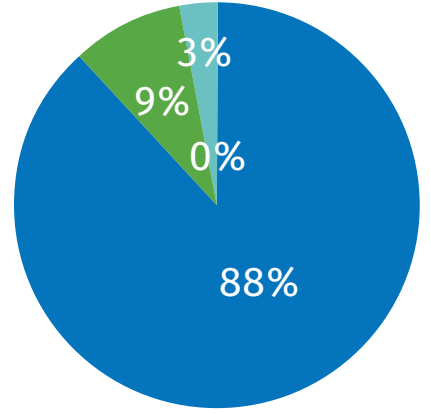

Surgical experience

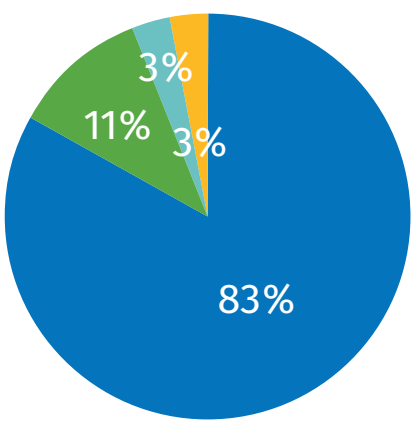

Resource in theatre

\section{\begin{tabular}{l|l|l|l|l}
4 & 3 & 2 & 1 & $4=$ high rating, $1=$ low rating
\end{tabular}}

Figure 1: The impact of PNSA practice on their practice - perioperative staff responses

'As a new staff member, [I have found] the PNSAs have been extremely helpful with information regarding the department, instruments and operation/surgeon preferences.'

'They're great, make our jobs easier.'

'The role of the PNSA is helpful to theatre staff as they have a holistic approach to delivery of efficient patient care.'

\section{PNSAs}

The mean years of experience as a PNSA were four ( $s=2$ ). Most PNSAs travelled from the close metropolitan area of Brisbane to the regional Sunshine Coast area to work at SCUPH. Two PNSAs had temporarily or permanently relocated from interstate to gain more PNSA experience at SCUPH.
Of the twelve PNSAs surveyed, two were PNPS with a master's degree as their nurse practitioner qualification and one of the PNSA qualifications, an additional two held master's level PNSA qualifications and were enrolled in Master of Nurse Practitioner Studies. Of the eight PNSAs remaining, two completed a Master of Advanced Practice (PNSA) this semester, three are a little further from completion of a Master of Advanced Practice (PNSA), two have been conferred with a graduate certificate in the PNSA specialty and one is a new student in the certificate qualification of the PNSA specialty.

Sixty-seven per cent of PNSAs thought the SCUPH experience had a high or moderately high impact on their leadership skills and 67 per cent strongly agreed they had gained more experience (Figure 2). There was unanimous consensus among the PNSAs that they had positively contributed towards customer service, knowledge of surgeon preferences and served as a resource in the operating theatres. Ninetytwo per cent of PNSAs thought that the contribution they had provided to the Ramsay-Queensland Health contract had positively impacted on the role and professional standing of the PNSA at a local level on the Sunshine Coast but also within Queensland and on a national level. This can partly be attributed to surgeons from within Queensland or interstate performing a 'locum' contract at SCUPH and then returning to their base elsewhere. Several locum surgeons have asked how to access PNSA services for their primary place of practice.

\section{Surgeons}

Surgeons who responded to the survey were six orthopaedic surgeons, six general surgeons and one urologist. Three quarters (76 per cent) of responding surgeons were classified as visiting medical officers the others were employed in locum positions. Forty-five per cent of surgeons had worked with a non-medical surgical assistant in some form (mostly overseas) prior to their SCUPH experience. Surgeons unanimously agreed that PNSAs having prior perioperative experience was important and that PNSAs provided a supportive service to the perioperative team and acted as a resource. 68 per cent of surgeons are now using PNSAs for private lists and all surgeons agreed that PNSAs should have the ability to claim (procedural) assisting patient care remuneration through Medicare and private health funds (Table 1). 


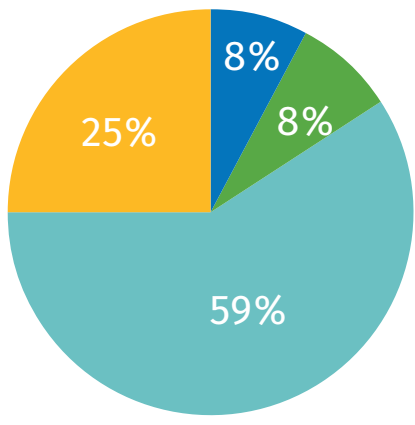

Leadership skills

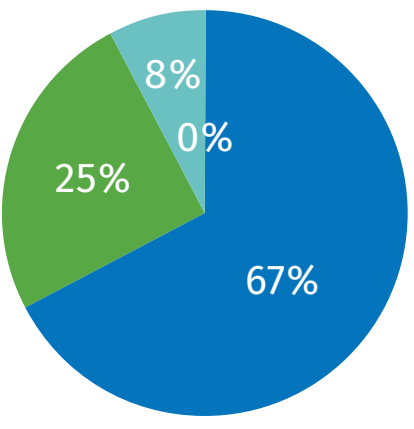

Experience gained

\section{$\begin{array}{llllll}4 & 3 & 2 & 1 & 4=\text { high rating, } 1=\text { low rating }\end{array}$}

Figure 2: PNSA rating of SCUPH experience on leadership skills and experience gained

\begin{tabular}{|l|c|}
\hline Statement & $\begin{array}{c}\text { Percentage of } \\
\text { surgeons who agreed }\end{array}$ \\
\hline Worked with a PNSA prior to SCUPH & $45 \%$ \\
\hline PNSAs provide a supportive service & $100 \%$ \\
\hline PNSAs having perioperative experience is important & $100 \%$ \\
\hline PNSAs are a resource to the perioperative team & $100 \%$ \\
\hline The PNSA as a resource is helpful & $100 \%$ \\
\hline Use a PNSA for private surgery & $68 \%$ \\
\hline $\begin{array}{l}\text { Experience at SCUPH influenced decision to use a } \\
\text { PNSA in private surgery }\end{array}$ & $73 \%$ \\
\hline $\begin{array}{l}\text { PNSAs should have ability to claim for assisting } \\
\text { services via Medicare and private health insurance }\end{array}$ & $100 \%$ \\
\hline
\end{tabular}

Table 1: Surgeon's responses

All surgeons agreed that PNSAs provide the following services: patient positioning/set-up, problem shooting equipment, surgical knowledge and wound management.

\section{Comments made by surgeons:}

'They (PNSAs) provide a fantastic service that is not adequately remunerated with current options.'

'Very competent, often much better than medical practitioners.'
'PNSAs provide a highly skilled perioperative service for the patients, typically better than a medically trained assistant.'

'Medicare and private health funds are insurance schemes (public) private insurance schemes) that provide payment for medical care. The PNSA service is part of that medical care and should not be excluded.'

'The help is provided professionally.'

'A valuable service.'

\section{Discussion}

Internationally, circumstances such as the implementation of the European Working Time Directive, have increased patronage of the non-medical surgical assistant ${ }^{20}$. The European Working Time Directive limits the working hours of training doctors ${ }^{5,21}$. Domestically the uptake of the PNSA was initially restrained, with remuneration issues still problematic in the private sector. However, the choice of medical professionals to seek an improved work-life balance and the overall feminisation of the medical profession have given credence to the role of the PNSA in Australia ${ }^{22,23}$. From a government perspective, a strategic objective of the Health Workforce Australia Work Plan 2013-14 is to boost productivity with a focus within the plan on 'supporting national implementation of new workforce roles'. More research into the capacity of the role of the PNSA to increase productivity within the perioperative cycle could complement Health Workforce Australia strategic objectives ${ }^{24}$.

Highlighted by these surveys, the opportunity for PNSAs to demonstrate their skills and training has been a positive experience for PNSAs, surgeons and the perioperative nurses working with them. This is confirmed not only in the positive comments from the surveys but the willingness of the hospital to extend the initial twomonth trial.

The PNSAs involved in this service have gained valuable clinical experience and been exposed to specialties outside their usual practice. This experience has also broadened the exposure of the role of the PNSA not only in Queensland but Australia-wide and demonstrated to the health care community that PNSAs are a viable option. 
It is acknowledged that not all comments from the perioperative nurse are positive. One area that requires attention is the perceived confusion in role delineation between PNSA and scrub nurse. Role delineation concerns have been identified in many areas of health care where advanced practice nursing is practiced 22,25 .

Each of the PNSAs has been able to experience the autonomy of a self-employed provider of services, as they do not work as an employee in the circumstances outlined here. The initial remuneration rate was benchmarked on the Queensland Health Advanced Practice Nurse casual pay rate. Without governance by an employment award, the service has developed flexibility to cover emergency theatres, 'on-call' commitments and prolonged surgical lists.

When comparing the rating on leadership between the PNSA and perioperative staff responses it appears that the perioperative staff rate the leadership of the PNSA practice higher than the PNSAs. This would be an interesting area for future investigation and role development.

As this service has been provided at a new hospital, several of the comments by the perioperative staff, including management, have been about the support and resource that the PNSA have provided in the start-up process for the perioperative department. Does the inclusion of a PNSA, Advanced Practice Nurse or NP in the setup of a new service or facility have a positive impact on staff, medical practitioners and clients?

With limited published information about PNSA, this health care facility provides a PNSA-rich environment to support future investigations and contribute to the literature. Future research could include investigating the role of the PNSA and impact on patient outcomes or cost effectiveness. Role delineation in the context of advanced practice could also be investigated.

\section{Conclusion}

Communication and clear delineation of roles when initiating a service of this type are important ${ }^{25-27}$. The positive experience gained in the form of professional growth of the PNSA and satisfaction from perioperative staff and surgeons at SCUPH supports the statement that Advanced Practice Nurses 'are and will continue to be an important provider of cost effective and accessible healthcare in the $21^{\text {st }}$ Century'28.

It has been demonstrated from these surveys that customers in the form of perioperative nursing staff and surgeons within this public/ private contract at SCUPH, have been clearly satisfied with the professional services of the PNSAs. The authors aim to expand the monitoring of the service provided by PNSAs at this facility. The PNSAs providing services at SCUPH comprise a large cohort and should be used to expand the knowledge of the role.

\section{References}

1. Smith C, Mannion N. A Change in tide: Rippling from local to national. Perioperative Nurses Association of Queensland Annual Conference. Sunshine Coast; 2015.

2. About Sunshine Coast University Private Hospital [Internet]. Ramsay Health Care;2015 [cited 2015 May 3]. Available from: www.sunshinecoastuniversityprivate.com au/Our-Hospital/default.aspx2015

3. The Australian College of Operating Room Nurses Ltd. ACORN Standards for Perioperative Nursing, 2014-2015. Adelaide, South Australia; 2014.

4. Hall SL, Quick J, Hall A, Jones A. Surgical assistance - who can help? Ann R Coll Surg Engl 2014;96:244-6.
5. Quick J, Hall S, Jones A. The surgical care practitioner role problems and possible solutions from nurses in the UK offered to RNFSA colleagues in New Zealand. Dissector 2014;42(1):32-4.

6. Morgan S. What are the differences in nurse practitioner training and scope of practice in the US and UK? Nurs Times 2010;106(27):21-4.

7. Mumford V, Haas M. Nurse Practitioners and Physician Assistants: Adapting models of care to changing demographics. University of Technology Sydney; 2014 [cited 2015 Jan 1]. Available from: http://refinephc.org.au

8. Kneebone RL, Nestel D, Chrzanowska J, Barnet AE, Darzi A. Innovative training for new surgical roles - the place of evaluation. Med Educ 2006;40(10):987-94.

9. Independent Healthcare Advisory Services. Surgical Care Practitioners Policy Statement. In: Independent Healthcare Advisory Services, editor; 2006.

10. College of Operating Department Practitioners. Curriculum Document. In: College of Operating Department Practitioners, editor; 2011. Available from: www.codp.org.uk/documents/BSc $\% 20$ Curriculum_April\%202011.pdf

11. Quick J. The role of the surgical care practitioner within the surgical team. $\mathrm{Br}$ J Nurs 2013;22(13):759-65. 
12. Lynn A, Brownie S. The perioperative nurse surgeon's assistant: issues and challenges associated with this emerging advanced practice nursing role in Australia; 2013.

13. Bryant E. Perioperative Nurse Surgeon's Assistants in day surgery: An emerging role within Australia's health system. Ambulatory Care 2010; July:25-7.

14. Hamlin L, Dobson J, Cook L. Perioperative nurse practitioners (NP) - the first two perioperative NPS are authorised in NSW. ACORN J 2010;23(4):6-10.

15. Brennan B. The registered nurse as a first surgical assistant: the 'downunder' experience. Semin Periop Nurs 2001;10(2):108-14.

16. William G, Crilly J, Souter J, Veach K, Good $\mathrm{N}$. A statewide validation and utilisation study of the Queensland emergency nursing workforce tool. J Nurs Manag 2014;22:107688.

17. School of Health and Human Sciences. Southern Cross University; 2014. Available from: www.scu.edu.au/healthscience
18. Gardner A, Gardner G. A trial of nurse practitioner scope of practice. J Adv Nurs 2005; 49(2):135-45.

19. Willows R. Perioperative nurse surgeon assistant role within the cardio-thoracic unit of Royal Hobart Hospital. Day Surgery Australia 2012;11(1).

20. Quick J, Hall S. Non-medical surgical assistants: a review. The Clinical Services Journal 2014; June:75-8.

21. Pickersgill T. The European working time directive for doctors in training. Br Med J 2001;Dec:323-4.

22. Van Der Weyden M. Task transfer: another pressure for evolution of the medical profession. Med J Aust 2006;185(1):29-31.

23. Doctors and Nurses [Internet]. Canberra: Australian Bureau of Statistics. Available from:www.abs.gov.au/AUSSTATS/abs@.nsf/ Lookup/4102.0Main+Features20April+ 2013\#p22011

24. Health Workforce Australia Work Plan 2013-2014 [Internet]. Health Workforce
Australia. Available from: www. hwa.gov.au/ sites/uploads/HWA-Work-plan-2013-14_VF_ LR.pdf 2013

25. Kirkpatrick K, Lavoie-Tremblay M, Ritchie JA, Lamothe L, Doran D. Boundary work and the introduction of acute care nurse practitioners in healthcare teams. J Adv Nurs 2012;68(7):1504-15.

26. Hurlock-Chorostecki C, Forchuk C, Orchard C, van Soeren M, Reeves S. Labour saver or building a cohesive interprofessional team? The role of the nurse practitioner within hospitals. J Interprof Care 2013;28(3):260-6.

27. MacLellan L, Higgins I, Levett-Jones T. Medical acceptance of the nurse practitioner role in Australia: A decade on. J Am Assoc Nurse Pract 2015;27(3):152-9.

28. Duffield C, Gardner G, Chang AM, CatlingPaull C. Advanced nursing practice: a global perspective. Collegian 2009;16(2):55-62. 